\title{
Prejuicios, incomodidades y rechazos: música, territorialidades y conflictos en el Brasil contemporáneo
}

\section{Felipe Trotta}

Universidade Federal Fluminense, Brasil

trotta.felipe@gmail.com

\section{RESUMEN}

La música es un importante instrumento para la construcción de identidades y vínculos territoriales y establece simbologías e imaginarios compartidos que estructuran barrios, ciudades y naciones. Simultáneamente, articula segregaciones sobre la base de actitudes y sentimientos de negación, rechazo, impertinencias y prejuicios con relación a cuestiones territoriales o de género. En este artículo se analizan casos de los géneros musicales brasileños samba, forró y la música sertaneja, todos ellos marcadores de espacios específicos en las jerarquías simbólicas de la nación y, por eso mismo, agentes de conflictos musicales, simbólicos y geográficos.

Palabras clave: música popular, identidad, territorios, prejuicios.

\section{Prejudices, annoyances and rejections: music territorialities and conflicts in contemporary Brazil}

ABSTRACT

Music is an important artefact that helps people to construct identities and territorial links, establishing shared imaginaries and symbols that, on their turn, structure ideas about places such as neighbourhoods, cities, and nations. At the same time, music marks distinctions between them, mostly through negative feelings; rejections and prejudices against genres and territories. In this article, the cases of Brazilian genres samba, forró and sertanejo are analysed, taking them as markers of specific territories and spaces in 
the nation's hierarchies. Therefore, they can be thought as agents of music conflicts which are intermingled with symbolic and geographic struggles.

Keywords: popular music, identity, territories, prejudice.

\section{Preconceitos, incômodos e rechaços: música, territorialidades e conflitos no Brasil contemporâneo}

RESUMO

A música é um artefato importante na construção de identidades e vínculos territoriais, estabelecendo simbologias e imaginários compartilhados que estruturam bairros, cidades, nações. Simultaneamente, articula segregações baseadas em atitudes e sentimentos de negação; rechaços, incômodos e preconceitos contra gêneros e territórios. Neste artigo são analisados os casos dos gêneros musicais brasileiros samba, forró e sertanejo, marcadores de espaços específicos nas hierarquias simbólicas da nação e, por isso mesmo, agentes de conflitos musicais, simbólicos e geográficos.

Palavras-chave: música popular, identidade, territórios, preconceito. 
La relación entre prácticas musicales, identidades y vínculos territoriales ha sido abordada en diversas investigaciones durante décadas. En cuanto práctica cultural constructora de sentido y pertenencia, oír determinados repertorios musicales (y tocar, bailar, hablar acerca de, y todas las acciones relacionadas con la música que ejercemos cotidianamente) nos pone en contacto con ideas que, muchas veces, son atravesadas por la noción de espacio. Más que eso: la música es un operador fundamental para la construcción de pertenencias e identificaciones territoriales. Este proceso suele ser analizado desde el punto de escucha (y de vista) de los individuos y grupos que realizan la práctica musical. Para ellos, la música funciona como una herramienta de integración estética, ética y política en un determinado ambiente social y comportamental, donde se matizan valores compartidos que operan en un circuito de intensos intercambios entre sonoridades y espacialidades.

Sin embargo, lo que quisiera profundizar en este texto es otro sesgo crucial en la articulación entre música e identidades territoriales, que es el ejercicio de la otredad. Vinculada con territorios específicos y casi siempre con un perfil sociocultural definido y comúnmente estereotipado, la circulación de músicas produce una reacción que no siempre es de adhesión o comunión. Muchas veces, estas prácticas musicales son recibidas en contextos externos a los de su producción con sentimientos encontrados, de interés y curiosidad, así como de rechazo e incomodidad, y atravesados por diversos prejuicios.

Los procesos de formación identitaria por y a través de la música se suscitan de formas inesperadas, mediados por relaciones de poder: filtros raciales, de género y socioeconómicos pueden actuar para polarizar sectores de la sociedad, marginalizar grupos de personas del poder económico y político central y silenciar voces culturales alternativas u opuestas (Connel y Gibson, 2003, p. 15).

Las territorialidades musicales actúan como demarcadores importantes de pertenencias, que a su vez promueven y crean conflictos y tensiones sociales de diferentes formas. Los lugares y sus sonoridades establecen conexiones entre 
valores, ideologías y grupos sociales que interactúan a partir de la experiencia musical, negociando otredades y enfrentamientos éticos, comportamentales, estéticos y morales.

En este artículo, a partir del análisis de algunos géneros musicales brasileños estrechamente conectados con determinados espacios geográficos y redes de identificación social, cultural y política, hablaré sobre las maneras difusas y contradictorias en que los enfrentamientos sociales se experimentan y procesan a través de la música. Algunos casos particulares servirán de estímulos para esta reflexión, aunque correspondan a una pequeña parte de una gran diversidad territorial y musical del país continental. En estos enfrentamientos, opté por adoptar el estudio a partir de algunos géneros musicales, entendidos como conjuntos de repertorios musicales y culturales que articulan determinados valores compartidos (Frith, 1998; Fabbri, 1982; Jannoti Jr., 2004). Es evidente que los géneros musicales no forman conjuntos homogéneos de sonoridades y valores, sino solo puertas de entrada amplias, que permiten discutir algunos movimientos sobre sus imaginarios, adhesiones y rechazos.

El punto de inflexión inicial de este texto y varios discursos sobre música e identidad nacional en Brasil es el género samba ${ }^{1}$ y su atávica asociación con Río de Janeiro. La ciudad más turística y más divulgada interna y externamente en la publicidad sobre Brasil es también plataforma primaria de sentimientos compartidos de nación, construida en gran parte a través de prácticas musicales. El samba y su desdoblamiento menos prestigioso, el pagode [fiesta donde las personas se reúnen para disfrutar de la música samba, tomar cerveza, comer parrillada, etc.], funcionan como marcos de este imaginario de nacionalidad, construido en Río. Más recientemente, junto con el funk, el samba y el pagode encarnan y crean modos de sentir, ser, oír y ver el imaginario carioca, siempre pensado a partir de una asimetría social aguda, metaforizada en términos territoriales como «morro» [cerros], «suburbio» y «favela».

Si Río es imaginado como polo central de un determinado imaginario nacional, dicha centralidad se ve tensada también por otros géneros musicales que van a problematizar constantemente esta posición hegemónica de la antigua capital federal. Por un lado, el forró [ritmo de baile de origen cearense] del nordeste de Brasil va a establecer a partir de los años 1940 un reconocimiento musical de regionalidad, asentándose — a partir del mercado musical carioca — como música

Si bien la palabra termina en «a», hemos optado por usarla como en portugués, en masculino, para evitar cualquier confusión con la zamba argentina. 
característica del nordeste, basado en el sertón de la región, tierra de cultivo de caña de azúcar, maíz y de ganadería. Algunas décadas más tarde, la música caipira, también fuertemente asociada con el interior agrario del centro oeste y sudeste de Brasil, desemboca en una versión pop urbanizada, rebautizándola como música sertaneja [country]. Una vez más, el vínculo territorial se destaca en un esfuerzo de referenciar geográficamente determinadas sonoridades, valores y conjuntos de ideas. En ambos casos, el conjunto de oposiciones y tensiones producidas por la música encarna maneras de pensar y desarrollar la dicotomía campo versus ciudad, metáfora territorial del eterno enfrentamiento entre tradición y modernidad, arcaísmo y cosmopolitismo. Lo curioso de todo este proceso es que, desde la década de 1990, la música sertaneja pop y urbanizada ocupa el mainstream del mercado musical nacional, siendo actualmente, sin duda, la música nacional por excelencia, oída, cantada e integrada a todos los cantos del país.

Dentro de una maraña compleja de sonidos y territorios, se construyen y comparten jerarquías estéticas, sociales y políticas, que se (con)funden con los géneros musicales de cada espacio. El funk será emblema de una joven vitalidad negra y periférica, siempre tomado con desconfianza y curiosidad por la crítica cultural, por gestores de políticas públicas y por la policía. Será música de la favela y de favelados, reconocida y estereotipada como de bajo valor estético y social. En este movimiento, el samba, asociado al término morro, ocupa un rango de mayor prestigio de músicas producidas en ambientes «pobres», reconociéndola como válida por su longevidad y su historial de agregación social. Ahora el pagode, variante suburbana y favelada del samba, padece de un desprestigio impregnado de ambigüedades. El nordeste continúa siendo una región descalificada en el ámbito nacional, tierra de sequía, sufrimiento e ingenuidad, símbolo agrario del atraso y lo antimoderno. Y lo mismo ocurre con su música: el forró. Por otro lado, el interior rico de la agroindustria y la tecnología rural estará asociado con la música sertaneja, que, junto con su romanticismo idealizado, alcanza a un enorme contingente poblacional, incluso si es rechazado por la crítica y la intelectualidad urbana.

Todas estas prácticas musicales integran un universo contradictorio de sonidos, adhesiones y rechazos que circulan por el mercado musical y por la sociedad brasileña. Se trata de un escenario de enfrentamientos y conflictos que disputan preferencias estéticas, comportamentales y políticas, atravesadas por juegos de elaboración sobre la nacionalidad, las identidades sexuales y étnicas, las desigualdades sociales y los valores compartidos. Los territorios activados por la experiencia musical son imaginados y procesados como vectores de constitución 
de segregaciones y filiaciones entre grupos sociales, demarcados por vinculaciones espaciales, socioeconómicas, educativas e ideológicas.

¡Pero vayamos por partes!

\section{FAVELA, MORRO, SUBURBIO Y EL IMAGINARIO CARIOCA (¿AÚN?) DOMINANTE}

Río de Janeiro fue, durante más de un siglo, epicentro político y cultural de Brasil. Desde inicios del siglo XIX, con la llegada de la Corte Portuguesa a la ciudad, la brasilidad fue pensada, escrita, cantada y representada partiendo de los márgenes de la Bahía de Guanabara. Esta posición hegemónica del imaginario carioca en la construcción de la nacionalidad brasileña se revela fuertemente en la historiografía de la música popular nacional, contada en torno al surgimiento del samba a inicios del siglo XX. De esta manera, las jerarquías geográficas de la ciudad funcionan como metonimias de desigualdades sociales variadas del país, procesadas a través de repertorios musicales. El samba es una referencia importante de estos enfrentamientos. En su repertorio, divulgado desde finales de los años 1930 por la radio masiva, se crean ciertos imaginarios sobre tensiones e identidades geográficas, dando forma a un discurso sobre la brasilidad parcialmente apropiado en varias regiones del país.

En el discurso fundador del samba (alrededor de las décadas de 1920 y 1930), «los cerros» son considerados un espacio social, musical y geográfico fundamental. Los cerros de la ciudad de Río fueron ocupados durante las primeras décadas del siglo XX por poblaciones pobres, en su mayoría negras, que venían a buscar trabajo en la capital federal después del final de la esclavitud en 1888. En el imaginario de la ciudad, el «morro», es decir, los cerros ${ }^{2}$ se convierten en este territorio atravesado por numerosas precariedades, constituyéndose como símbolo social negativo, opuesto al asfalto o incluso a la ciudad. El samba rápidamente será reconocido como símbolo de una práctica cultural de los cerros, y en su repertorio este discurso de oposición se creará y debatirá. Atravesando letras de canciones, entrevistas de sambistas y reportajes en la prensa, el samba se configura como síntesis de un imaginario cultural que conjuga factores

2 La palabra morro también existe en español y se refiere, entre otros, a una forma particular de cerro redondeado, escarpado, o con algo prominente. La expresión «de los cerros» en plural, en cambio, se usa para decir «viene de los cerros» lo que significa que la persona es salvaje, o no educada, y pobre. De aqui en adelante usaremos la expresión «los cerros» para traducir morro del portugués. 
determinantes de identidad, étnicos, sociales y comportamentales materializados en un repertorio argumentativo complejo y en un patrón rítmico característico. Este patrón, que Carlos Sandroni denomina «paradigma do Estácio» sería una especie de encarnación rítmica de «un compromiso posible entre los polirritmos afrobrasileños y el lenguaje musical de la radio y el disco» (2012, p. 224). El samba y los cerros, por lo tanto, ocupan el mercado musical nacional como referencias de una (utópica) integración social y étnica, mezclando negros, mulatos y blancos en una sociedad mestiza y única ${ }^{3}$.

La consolidación de una sonoridad característica para el samba se inicia en este período, pero solo se consolida en disco en la década de 1960, cuando el concepto de autenticidad del género pasa a ser registrado en la formación instrumental de guitarra, cavaquinho, tamborín y pandereta. A estos instrumentos se suma un patrón vocal característico, otros instrumentos de percusión y una noción difusa de «batucada», configurando un sonido propio para el samba, tomado como referencial. Lo que es interesante subrayar aquí es que, durante gran parte del siglo XX, la consolidación de el samba, como «voz del cerro» ${ }^{4}$, sintetiza también un discurso conciliador entre clases al asumir la función de «traer alegría» $\aleph^{5}$ a la ciudad o de admirar «boquiabierto $»^{6}$ su belleza.

Esa hegemonía del samba como portavoz de los cerros va poco a poco ampliándose e incorporando otros marcadores geográficos significativos. Una primera designación que resalta la ocupación de los cerros es favela ${ }^{7}$.

3 La tesis del mestizaje ha sido duramente criticada en las últimas décadas por su asociación con una ideología que buscaba borrar la crueldad de la esclavitud en un discurso idílico de integración de los negros en la sociedad brasileña, algo realizado de modo particularmente precario, segregador y violento.

4 Título de famosa canción de autoría del compositor Zé Ketti, 1955.

5 Verso de la canción «A voz do morro» [La voz del cerro], de Zé Ketti, que dice: «Eu sou o samba / Sou natural daqui do Rio de Janeiro / Sou eu quem levo a alegria / Para milhões de corações brasileiros» [Yo soy la samba / Soy natural de aquí de Río de Janeiro / Soy yo quien traigo la alegría / Para millones de corazones brasileños].

6 Verso de «Cidade mulher» [Ciudad mujer], de Paulo da Portela, que dice: «Cidade, quem te fala é um sambista / Anteprojeto de artista, seu grande admirador / E confesso boquiaberto de manhã quando desperto com tamanho esplendor» [Ciudad, quien te habla es un sambista / Anteproyecto de artista, su gran admirador / Me confieso boquiabierto por la mañana cuando despierto con tamaño esplendor].

7 El Morro da Favela fue el segundo nombre dado al cerro situado en el centro de la ciudad de Río, ocupado a finales del siglo XIX por soldados que regresaban de la sangrienta Guerra de Canudos, en el sertón de Bahía. Al llegar a Río y no recibir alojamiento conforme a lo prometido, tomaron la «providencia» de ocupar el cerro. Se le conoció inicialmente como «Morro da Providência» y luego como «Morro da Favela», en homenaje a una vegetación de la región de Canudos. Hoy en día, el cerro regresó a su denominación original y el término 
Con el pasar de los años, el término pasó de sustantivo propio a común, designando cualquier área de ocupación desordenada realizada por ciudadanos de bajo poder adquisitivo, con construcciones precarias y ausencia de servicios básicos. Así, a diferencia del término los cerros, favela destaca el perfil sociocultural de las viviendas y sus moradores y no la topografía del espacio de la ocupación. Además, permite que se desarrolle un conjunto de estigmas socioculturales en torno al personaje favelado, siempre asociado con diversas descalificaciones sociales. El favelado es, según este estigma, un ser marginal, habitante de una región con poca normativa civilizatoria, en un contexto de violencia, insalubridad, promiscuidad y baja educación.

En este mismo sentido, el término suburbio comienza a emplearse cada vez más a partir de la mitad del siglo XX para referirse a barrios distantes del centro de la ciudad, ocupados en las márgenes de los ramales de la línea ferroviaria construida a finales del siglo XIX. A pesar de describir un conjunto de barrios a partir de su distancia del centro, el término suburbio también incorporará un sentido social, puesto que dichos barrios van siendo poblados poco a poco por poblaciones marginadas, empobrecidas y mayoritariamente negras.

Hoy en día, la idea de suburbio que forma parte del dominio público de Río de Janeiro, más que una denominación geográfica que comprende el norte de la ciudad que abarca barrios cortados por las vías de tren de la Central de Brasil y de Leopoldina, se refiere a su oposición con relación a la Zona Sur con respecto a su estatus social, sinónimo de pobreza, provincianismo y anacronismo (Oliveira, 2016, p. 59).

A partir de la década de 1960, y principalmente 1970, una serie de transformaciones en la sociedad brasileña rediseñan las jerarquías geográficas y sociales de la ciudad. Con la popularización de la televisión y los medios masivos, más integrados a centros de producción nacional e internacional (Ortiz, 2001), el mercado musical fue tomado poco a poco por repertorios anglófonos, lo que resaltaba políticas de estado de alineación al capitalismo estadounidense. Este movimiento, iniciado ya a finales de la década de 1950, desplaza a los sambistas a espacios circunscritos, fuera del enorme mercado musical. En los suburbios y en los cerros, ruedas de samba espontáneas van ganando espacio y comercializándose como opciones de esparcimiento no solamente para los moradores de dichas

favela pasó a referirse a toda ocupación precaria, casi siempre ilegal, de construcciones habitadas por ciudadanos de bajo poder adquisitivo, independientemente de estar ubicadas o no en cerros. 
áreas, sino además para públicos intelectualizados que buscaban acercarse a la cultura popular. Es cuando la informalidad de las ruedas de samba va gradualmente ganando otro nombre - pagode - que destaca su carácter no discográfico. Un término que tendería a ser empleado por la élite financiera e incluso por la prensa con fuerte carga negativa, vinculado a confusión, griterío, incomodidad y consumo de alcohol (Trotta, 2015).

$\mathrm{Si}$, en un primer momento, los términos los cerros, favela y suburbio se van a emplear de manera estrecha con el samba y la estructuración de las escuelas de samba (tanto en los cerros más cercanos al centro de la ciudad como en los suburbios), poco a poco cada uno de los términos va adoptando una característica simbólica propia, acompañado de cerca por sonoridades y estilos de vida que cruzan los imaginarios y jerarquías geográficos de la ciudad. Morro asume menor índice de estigmatización, dado que es un término vinculado a una historia romantizada del samba e identificada con vínculos comunitarios que se anteponen a las precariedades del lugar. Evidentemente este romanticismo es experimentado también con cierta ambigüedad, pues el avance del tráfico de drogas en la ciudad estará asociado en la prensa exactamente con el vocablo morro, que destaca la topografía favorable al atrincheramiento y escondite de los criminales. Sin embargo, cuando entran en escena las narrativas musicales, el término morro se vincula prioritariamente con el samba históricamente consagrado, consecuencia de contribuciones de varios sectores de la sociedad y responsable de determinados ejes de construcción de la identidad nacional (Vianna, 1995; Sandroni, 2012). Es el samba de los cerros el que ocupa un lugar destacado en la jerarquía de las sonoridades «populares», tanto en su expresión turística y grandiosa (a través de las escuelas de samba y de sus vibrantes baterías formadas por trescientos percusionistas) (Araújo, 1992) como en su versión mercantil, con el trabajo de compositores e intérpretes que dominaron las radios brasileñas desde la década de 1930 hasta los años 1960. Para el samba de este universo, el de los cerros es una especie de sello de calidad y autenticidad, que demarca orígenes que eventualmente son incorporados a los propios nombres artísticos de algunos sambistas ${ }^{8}$.

Al mismo tiempo, se observa en esta época el surgimiento de una juventud negra formada por una clase media baja habitante de los suburbios que empieza a identificarse con determinadas sonoridades de la música negra internacional y

\footnotetext{
Los sambistas con frecuencia son conocidos por una identificación afectiva (reforzada por el uso del diminutivo) con su morro de origen, muchas veces vinculada con un gremio carnavalesco reconocido. Tantinho da Mangueira, Jorginho do Império, Paulo da Portela, Marquinhos de Osvaldo Cruz y Martinho da Vila son algunos de los numerosos ejemplos.
} 
desplazar los mecanismos de identificación sobre la propia idea de negritud. Este movimiento es simultáneo al cambio de la capital federal para Brasilia (que ocurre en 1960 pero que va a generar consecuencias directas por varios años posteriores) y la progresiva pérdida de la capacidad de Río de definir culturalmente los rasgos de la cultura nacional. En los suburbios, las fiestas black hacen circular un conjunto de identificaciones que dialogan con la soul music anglófona, respondiendo así tanto por la identificación negra y pobre como por la pertenencia a un universo joven, cosmopolita y tecnológico (Oliveira, 2016). En un momento de exacerbada tensión política y social, en el contexto del golpe militar (1964-1985), los bailes black crean nuevos conjuntos de significados para las disparidades geográficas y sociales, que vuelven complejas las identificaciones étnicas y culturales en un contexto de progresiva mundialización (Ortiz, 2001). El suburbio comienza a revelarse entonces no solo como espacio de escuelas de samba consagradas o de los pagodes, sino además de animados bailes jóvenes que incorporan sonoridades cosmopolitas del soul, pop, reggae y rock.

Las fiestas black de los suburbios son denominadas el inicio de un tipo de apropiación cultural que se extenderá a las favelas (en los cerros), convirtiéndose en uno de los fenómenos culturales y musicales más importantes de finales del siglo XX: el funk carioca (Palombini, 2010; Essinger, 2005). Identificado como «música electrónica popular brasileña» (Pereira de Sá, 2007, p. 13) o como «el primer género brasileño de dance music electrónica» (Palombini, 2010, p. 103), el funk surge al final de la década de 1980 protagonizado por una juventud negra habitante de las favelas a partir de apropiaciones tecnológicas de varios estilos electrónicos como el house y el Miami bass. Este movimiento doble de incorporación y recreación de sonoridades y técnicas del mundo anglófono permite al funk captar ideas de juventud transnacionales y acomodarlas en el territorio de los bailes en las favelas cariocas, en un proceso de intensa circularidad (Pereira de Sá, 2007). Sin embargo, al mismo tiempo, el protagonismo de jóvenes negros y favelados en esta apropiación festiva produjo un movimiento de estigmatización intenso con relación al funk, asociándose a delitos, violencia y peligro. Al analizar innumerables temas en la prensa a inicios de los años 1990 acerca del funk, el investigador Micael Herschmann identifica que el género será continuamente presentado como vector de violencia, en un proceso de «demonización» que, paradójicamente, acaba produciendo también una «glamorización» (2005, pp. 115-118). En este punto, favela se convierte en un vocablo polisémico, accionado como encarnación de precariedades y violencias y también como vector de actividad creativa. En este enfrentamiento simbólico, el estigma incluso hoy 
sobresale en diversos contextos de circulación del funk, aunque en los últimos años diferentes acciones políticas hayan sido efectivas en disminuir el prejuicio contra el funk y ampliar su circulación en la sociedad (Trotta, 2016).

Lo que me gustaría mantener aquí es que las diferencias sociales materializadas y elaboradas por las prácticas musicales son fuertemente atravesadas por vinculaciones geográficas y territoriales, que, en el caso de Río, adopta términos y (des)calificaciones específicos relacionados con conjuntos de barrios (suburbio), ocupación desordenada de áreas de elevación geográfica (cerros) o de cualquier espacio urbano no habitado en que se instala precariamente un grupo poblacional (favela). El samba de los cerros, el pagode del suburbio o el funk de la favela funcionan, en el contexto de las jerarquías sonoras y musicales de la ciudad de Río, como demarcadores y elaboradores de estas distintas diferencias y enfrentamientos sociales que habitan la ciudad.

Sucede que la ciudad de Río posee actualmente un carácter contradictorio en el imaginario nacional. Por un lado, Río aún es irradiadora importante de discursos sobre la identidad brasileña, siendo eje de reverberación de maneras de ser, estar y compartir códigos culturales todavía con bastante repercusión en varias localidades (un elemento importante de ello es la localización de la Rede Globo en Río, responsable de una determinada idea de nación diariamente exhibida en las pantallas de la televisión de todo el país). Los imaginarios y prejuicios asociados al samba, pagode y funk, en este sentido, son adoptados en varias otras ciudades brasileñas, resonando valores, ideas y negatividades. En otros casos, sin embargo, las demarcaciones musicales y geográficas van a aislar regiones en el enorme territorio nacional, estableciendo jerarquías simbólicas negociadas sonoramente a través de determinados géneros musicales y repertorios. De alguna manera, la centralidad de Río es negada — o por lo menos tensada - por otras prácticas musicales que despiertan un enfrentamiento jerárquico entre lugares del país, poniendo en escena desigualdades regionales. Uno de estos casos es el de la región nordeste y su música más característica: el forró.

\section{EL NORDESTE VISTO DESDE EL SUR Y EL PREJUICIO}

La región nordeste de Brasil fue «inventada» durante la primera mitad del siglo XX como estrategia política de las élites de algunos estados del Norte para obtener financiamientos del gobierno central (en Río). Según el historiador Durval Muniz de Albuquerque Junior (2009), el proyecto tuvo desde el inicio la adhesión de artistas (especialmente pintores y escritores) e intelectuales de los estados nordestinos, 
que poco a poco fueron construyendo un imaginario común de la región. Publicado en 1937, el libro Nordeste, de Gilberto Freyre, resumía algunas de las características consideradas como fundamentales de una «civilización del azúcar».

El monocultivo latifundista y esclavocrático e, incluso, monosexual —el hombre noble, dueño de ingenios, que goza casi solo de los beneficios del dominio sobre la tierra y los esclavos - dio al perfil de la región lo que muestra de aguileño, aristocrático, caballeresco, aunque un aristocratismo, en cierta medida, mórbido, y una caballerosidad algunas veces sádica (Freyre, 2004, p. 38).

De esta construcción identitaria en torno al ambiente rural (donde el cultivo de caña de azúcar y el sistema esclavista son marcadores cruciales), el Nordeste será concebido a partir de una «geografía en ruinas» (Albuquerque Jr., 2009), en torno a la decadencia de la economía de los ingenios de caña y de las sequías resultantes, en parte, por la devastación del monocultivo extensivo. Por ello, el llamado «flagelo de la sequía» unirá ciertos estados nordestinos afectados por la sequía y objetos de atención de la recientemente creada Inspectoría Federal de Obras Contra las Sequías (IFOCS), en 1919 (Alburquerque Jr., 2009, p. 81). Como una acción de valorización y rescate del sertón seco, combinada con la élite azucarera de la región, el imaginario de la «identidad nordestina» se fue elaborando en torno al ambiente rural, la cultura de la caña y del maíz, las casas de barro, la renta, el sombrero de paja y el tejido de algodón estampado a colores. Objetos culturales de un pueblo humilde, pobre, sufrido, pero valiente, resistente, religioso y, a su manera, alegre y festivo. Pueblo que inicia incluso en el siglo XIX una serie de flujos migratorios hacia las capitales desarrolladas del sudeste brasileño, especialmente Río y São Paulo. Hasta mediados del siglo XX, con un intenso y continuo movimiento dramático de migración realizado por millares de personas, las grandes ciudades del sudeste brasileño fueron literalmente invadidas por sertanejos migrantes, que ocupaban puestos de trabajo de baja remuneración, principalmente en los sectores de servicios y construcción civil. Por lo tanto, rasgos de la «cultura nordestina» — especialmente rural - integrarán el escenario multicultural de las principales ciudades brasileñas, siendo reconocidos como elementos de una identidad migrante, agraria, auténtica e inculta.

A partir de mediados de los años 1940, este imaginario del Nordeste, ya consolidado en una geografía nacional, ganaría una sonoridad particular a través de la actuación del cantante, compositor y acordeonista Luiz Gonzaga, quien, viviendo en Río de Janeiro (¡siempre Río!), creó un género musical —el baião [ritmo del género forró]— que se nacionalizó a través de la radio como signo musical 
de la región nordeste. El trío formado por sanfona (nombre cariñoso utilizado en el Nordeste brasileño para designar al acordeón), triángulo y zabumba (una especie de bombo) se convierte en un emblema sonoro del nordeste, integrando un conjunto de referenciales «característicos» de la región (Trotta, 2014). En las letras de las canciones de Luiz Gonzaga, rápidamente seguido por varios otros cantantes y compositores, brotaba un Nordeste idílico, castigado por la sequía, conservador en costumbres y comportamiento, aunque afectuoso en la vida social y usado en los flirteos eróticos. Aparece en este imaginario divulgado en todo el territorio nacional un nordestino festivo, sufrido pero resistente, que escenifica su identidad en los bailes y canciones del baião, término que después de algún tiempo será sustituido por «forró» (Santos, 2014).

Otro aspecto importante de la narrativa nordestina en la música de Luiz Gonzaga y otros artistas nordestinos que adoptaron el baião y el forró como género musical y signo identitario ${ }^{9}$ es el carácter migrante de su canto y personajes. Reflejando su propia trayectoria (nacido en el interior de Pernambuco migrará a Río después de salir del servicio militar), la narrativa de gran parte de sus canciones describe el movimento de migración de individuos que huían de la sequía del sertón nordestino en busca de trabajo y dignidad en las metrópolis de Río y de São Paulo. Por esta razón, Albuquerque Junior destaca la construcción imaginaria del nordeste gonzagano como una creación de «espacios de nostalgia» (2009, p. 78).

El imaginario de la sequía y la precariedad del nordeste junto con el tipo de ocupación que el nordestino típico (con baja educación formal) conseguirá en las metrópolis terminan por construir de a pocos un grave prejuicio contra el nordeste, desde el centro sur. La región pasa a ser representante de una tradicionalidad inocente, rural y conservadora, que contrasta con las ansias de modernización, cosmopolitismo y urbanidad del Brasil de los años 1950 y 1960. En este contexto, el baião de Luiz Gonzaga, después de un poco más de una década de éxito, pasa a ser asociado con un universo de calificaciones negativas y reduce su impacto en el mercado en el momento en que el desarrollismo del presidente Juscelino Kubitschek (1956-1961) se consagra como vector fundamental de la cultura nacional. El «atraso» del baião y del nordeste estaba siendo sustituido por la «modernidad» del automóvil, de las carreteras, del bossa nova y de la nueva capital federal en el altiplano central del país.

Merecen ser destacados los artistas Jackson do Pandeiro, el Trio Nordestino, la cantante Marinês y el acordeonista Dominguinhos. Además de ellos, muchos otros artistas van a vincularse, a partir de las décadas de 1950 y 1960, al baião y al forró, construyendo un nuevo género musical en el mercado musical brasileño. 
El nordestino, entonces, por continuidad entre el imaginario «atrasado» del nordeste y sus habitantes, será estigmatizado en el imaginario nacional. El propio acento será reconocido en Río y en São Paulo como algo que marca y disminuye la importancia social y cultural del nordeste y el nordestino. En un importante trabajo sobre la elección de la paraibana Luíza Erundina para la prefectura de São Paulo, Maura Penna observa la forma como su origen nordestino fue continuamente reforzado por la prensa como demarcadora de una identidad descalificada.

Erundina es mujer, es nordestina y, con respecto a su origen social y a su militancia, es pobre. Cualquiera de estas referenciales permite la atribución de identidades que cargan la calificación de incompetente. El prejuicio contra el nordestino y el pobre estigmatiza ciertos rasgos, volviéndolos capaces de anular cualquier otro dato, como la formación académica y profesional de Erundina (Penna, 1992, p. 116, letra cursiva original).

La sonoridad de la sanfona y el forró funciona en este contexto como emblema sonoro de esta descalificación, que será tensada por la aparición, en los años 1990, de un «nuevo» forró, electrificado y pop. Conocido como forró electrónico, el forró pop que se desarrolla a partir de este período representará sonoramente una disminución en la importancia de la sanfona, substituida por el teclado, por el sonido cosmopolita de la guitarra-bajo-batería (Regev, 2013) y, posteriormente, por los metales (Trotta, 2014). Junto a este procesamiento sonoro, un conjunto de valores e ideas urbanos, modernizadores y mercantiles va a producir una música bailable y joven, buscando alejarse del referencial rural y atrasado de la identidad nordestina. Bandas como Mastruz com Leite, Limão com Mel y Calcinha Preta poco a poco dominan el mercado musical de la región, ocupando un nuevo mainstream regional (Trotta y Monteiro, 2008). En sus actuaciones, modelos e imaginarios de un nordestino festivo, masculinizado y valiente, ya no asociado al sufrimiento del campesino pobre en un entorno seco y sí al peón joven y exitoso de las fiestas de boyeros y ferias de exposiciones agrarias. El ambiente pop y cosmopolita de los grandiosos shows de forró electrónico cautiva a un público joven de ciudades pequeñas y medianas del interior del nordeste, aportando nuevas ideas y nuevas sonoridades para la construcción de la identidad nordestina.

Este proceso, comercialmente ganador en todos los nueve estados de la región nordeste, desencadena diversas críticas, especialmente procedentes de sectores identificados con una intelectualidad nordestina. Para este grupo social, el referencial rural y sertanejo de la nordestinidad es vector crucial de mantenimiento de la cohesión simbólica de la región. Sertón que agrega no solamente un conjunto 
de estereotipos humanos, sino también los elementos tomados como válidos de la construcción de la identidad nordestina, sonorizados por la sanfona.

Se instaura, por consiguiente, una oposición bastante dura entre los admiradores del forró tradicional (que pasó a llamarse también forró pé-de-serra en alusión al lugar imaginario del sertón gonzagano, al pie de la Serra do Araripe, sertón pernambucano, donde Luiz Gonzaga nació) y los jóvenes identificados con el ambiente pop comercial del forró electrónico. Un marco importante de este enfrentamiento será la creación, en 2002, en la ciudad de Recife, de la Sociedade dos Forrozeiros Pé de Serra E Ai, realizada a partir de un manifiesto escrito y divulgado por el compositor y activista Xico Bizerra.

LA SOCIEDADE DOS FORROZEIROS PÉ-DE-SERRA E AI!!!, grupo constituido por los firmantes, se hace público para exhortar al gobierno, comunidad artística, pueblo de la nación nordeste a unir esfuerzos por un pacto en defensa de nuestra más auténtica cultura popular, la música regional nordestina. La semilla un día sembrada por el rey del Baião, en Exu, debe merecer una mayor consideración por parte de todos, para garantizar la preservación de la música popular nordestina, hoy tan discriminada, no obstante, la calidad de su contenido melódico y poético. Es hora de abrir los ojos, todos, de manera que no permitamos que la riqueza de la musicalidad regional, cargada de emoción, pasión y amor telúrico se desvanezca, por nuestra falta de atención. La vocación de esta música es la belleza de la historia de un pueblo, sus cánticos y creencias, sus sueños y sus alegrías. Es nuestro deber preservar y ofrecer al público en general una oportunidad de apreciar y conocer su magnitud, cuya alma, por ser nordestina y universal, la legitima, cosiendo su sonoridad, los rasgos de su historia. En definitiva, no podemos privar al pueblo de este cantar nordestino tan bonito, porque está cargado de afecto y amor. (Xico Bizerra, letras cursivas originales. Disponible en el sitio $<$ www.forroboxote.mus.br>, acceso en: 16/06/2008).

Las referencias al ambiente rural en el manifiesto son didácticas en establecer y reforzar la convicción de que la identidad nordestina sonorizada por el forró debe ser pensada prioritariamente a partir del territorio sertanejo, encarnado en el manifiesto como lugar de afecto. Espacio físico que funciona en el imaginario del forró tradicional mucho más como símbolo de la autenticidad valorizada en el texto que concretamente como lugar o paisaje, dado que el mercado forrozeiro ocupa mayoritariamente las áreas centrales de las ciudades del interior del nordeste.

El enfrentamiento entre pé-de-serra y electrónico es la materialización musical de la amplia tensión entre tradición y modernidad y, en un plano más específico, de los debates y conflictos en torno a modelos de construcción 
de la identidad nordestina. Si el mundo rural provee los elementos para el refuerzo de puntos de apoyo compartidos sobre dicha identidad (sonoramente audibles en el trío instrumental sanfona-triángulo-bombo, el trío pé-de-serra), los impulsos cosmopolitas absorben otros modelos de familiaridad estética e ideológica, que acercan determinados públicos —en su mayoría jóvenes - de otras frases y afinidades conectados con el mundo urbano y el ambiente pop. Curioso en este proceso es el movimiento de aproximación de algunos artistas del forró electrónico de la llamada música sertaneja, género musical de origen rural (nuevamente la marca de la autenticidad), pero que se volvió electrificada y cosmopolita desde la década de 1980, asumiendo una posición hegemónica en el mercado musical nacional.

La marca territorial del sertón en la música sertaneja se refiere no al espacio de la sequía del interior nordestino, sino al espacio de abundancia y pujanza económica de la agroindustria del centro-oeste y sudeste brasileño, encarnando otras frases sobre la identidad regional y nacional. La sonoridad de la música sertaneja será un modelo cada vez más presente en los arreglos y shows de artistas identificados con el forró electrónico, en una especie de consolidación pop de prácticas musicales que buscan la reelaboración del imaginario negativo de lo rural.

\section{EL SERTANEJO: POPULARIDAD NACIONAL SIN RECONOCIMIENTO ESTÉTICO}

En 1982, las radios brasileñas fueron dominadas por una canción interpretada por el dúo sertanejo Chitãozinho y Xororó, titulada Fio de cabelo (Darci Rossi y Mariano). La guarania, acompañada por el rasgado característico de la guitarra y por el sintetizador modernizador, narra una historia de amor entonada en terceras paralelas y se vuelve un marco en el mercado discográfico nacional.

La canción fue importantísima en la historia de la música sertaneja porque extrapoló los límites de popularidad inaugurados por dúos anteriores. Por primera vez, la música sertaneja conseguía ventas por encima de un millón de discos, mostrando el potencial de aquel género [...] Con la canción Fio de cabelo se rompió una parte de la resistencia a lo sertanejo (Alonso, 2015, p. 201-202).

El éxito de la canción resumía un largo proceso de transformaciones en la llamada música caipira [del interior; del campo], tradición rural del interior de los estados de Goiás, São Paulo, Mato Grosso do Sul, Paraná y Santa Catarina, 
basada en la viola y en el canto en terceras paralelas, casi siempre con narrativas románticas ambientadas en el campo. El género obtuvo su primer éxito comercial todavía a finales de los años 1920, a través de la acción del productor e investigador Cornélio Pires, que grababa discos de artistas del interior y los vendía de ciudad en ciudad por el interior (Nepomuceno, 2005). La producción musical de este universo, sin embargo, resumía una serie de descalificaciones de la figura del caipira, personaje ingenuo, de baja instrucción, conservador, tosco en los gestos y modales, pero dotado al mismo tiempo de fina ironía que se confunde con su inocencia. Su música será percibida en las metrópolis centrales de la nación como «rústica e imperfecta, igual a sus creadores» (Mendívil, 2016, p. 84). Este conjunto de estereotipos fue materializado en la novela Jeca Tatu, de Monteiro Lobato, que lo define como símbolo del arcaísmo rural de Brasil, mediocridad que sustentaba una aristocracia política nefasta (Alonso, 2015, p. 29). En la década de 1950, Jeca Tatu fue llevada al cinema por Amácio Mazzaropi (1912-1981), en varias películas donde el personaje aparecía siempre en un contexto risible.

A partir de la década de 1960, la ideología modernizadora avanza también respecto de la música caipira y varios artistas van a buscar inspiración en los westerns estadounidenses e italianos para construir narrativas rurales de vaqueros y cowboys reprocesando el estigma negativo del caipira. Buscando aproximación con el rock y con la música country estadounidense, dúos como Leo Canhoto y Robertinho y Milionário y José Rico pasan a ocupar espacios importantes del mercado con una nueva música caipira, ya rebautizada como sertaneja. Evidentemente que este movimiento genera enfrentamientos entre el caipira y el nuevo sertanejo, demarcando polos distintos de apropiación del imaginario provinciano brasileño, atravesado por prejuicios y descalificaciones, e incluso por el argumento recurrente de la «autenticidad». Por lo general —y eso también ocurre en el mercado del forró-, hay una construcción simbólica establecida de valoración de las tradiciones rurales como dotadas de una brasilidad primordial, intrínseca y «profunda», que se materializa en prácticas musicales como la música caipira y el forró pé de serra. Son estos valores que son puestos en jaque por la aparición de la música sertaneja, ansiosa por incorporar referencias cosmopolitas en la indumentaria, las letras (con énfasis en el amor y abandono progresivo de las temáticas campestres y relacionadas con la naturaleza) y la sonoridad, con la incorporación de guitarras, bajo, batería, teclado y elementos de actuaciones que coquetean con el rock y el pop anglófono. En el caso de la música sertaneja, este proceso alcanza un momento decisivo con el éxito de Fio de cabelo. Al analizar la estética victoriosa defendida por los dúos sertanejos que se identifican 
con esta estética, la investigadora Rosa Nepomuceno establece una conexión entre el nuevo estilo y ciertos cambios en la economía rural procesados durante la década de 1980, que alteraron las dinámicas culturales y financieras del interior, especialmente relacionadas con los estados de São Paulo y Goiás.

La corriente musical liderada por Chitãozinho y Xororó vino a traducir este interior brasileño ahora próspero, harto, interconectado en línea al primer mundo y ávido por nuevos íconos de cultura y comportamiento, para soportar la bronca del peón que corcoveaba en la potente pick up, del ganadero que negociaba en dólares e iba en jet privado de una hacienda a otra, de sus hijos universitarios que hablaban inglés y oían música internacional, de los colonizadores con radiograbadora en la sala y satélite en el patio, son sertanejo bastante acabado, con arreglos actuales, envuelto por muchos megavatios de potencia (Nepomuceno, 2005, p. 203).

A partir de este momento, la denominada música sertaneja dominará el mercado musical brasileño, absorbiendo ideologías y sonoridades del «interior» y tensando la propia identidad nacional. Su auge ocurrió en la década de 1990, donde nuevos dúos de enorme éxito (como Leandro y Leonardo y Zezé Di Camargo y Luciano) surgieron en el mercado con gran éxito. Pero, nuevamente, la identificación con el universo rural, incluso cubierta de un ambiente sonoro y visual pop y cosmopolita fue duramente criticada por la intelectualidad urbana. Si el caipira tradicional se toma pedagógicamente como el hombre del interior inocente de reconocida autenticidad, la versión pop sertaneja de la música del interior rico brasileño será reconocida inmediatamente como dilución, fabricación, desnaturalización. En el discurso de la crítica, la atribución de una acción empresarial que se antepone a las cualidades estéticas. Es así que el entonces prestigioso crítico musical Tárik de Souza escribe sobre el show del dúo Leandro y Leonardo, en Río de Janeiro, en 1991:

Show malo. Nace el chabacano niño bien. Se instala el sertanejo nuevo rico [...] La aplanadora de la unanimidad nacional — que ya vio en un pasado remoto a cierto Chico Buarque - le otorga unos evasivos quince minutos de gloria, si bien el show del Canecão, que ellos protagonizan, dura una hora a más, antes de la repetición obligatoria. Pero no es fácil llenar todo este tiempo con repertorio tipo aguardiente, que apela a Simon \& Garfunkel [... ] y a Lupicínio Rodrigues $[\ldots]$ a bordo de un instrumental de restaurante de parrilladas, en una cervecería que ya recibió acordes de Tom Jobim (De Souza, 1991).

El periodista no está solo en las descalificaciones. El enorme éxito del sertanejo en todas las radios, casas de espectáculos y en los top ten de la industria 
discográfica de la década de 1990 será violentamente evaluado por la intelectualidad, que observaba la entrada definitiva de la sonoridad pop en la música nacional, mezclada con referencias (distantes e insuficientes, según los críticos) a prácticas musicales consideradas «auténticas», que perdían su valor estético.

En este período, un fenómeno interesante de desplazamiento territorial se conecta con la ampliación del mercado de música pop en Brasil, en consonancia con un contexto socioeconómico de intensificación de la globalización y neoliberalismo en América Latina. Río, que siempre fue eje de irradiación musical, pierde su capacidad de establecer éxitos nacionales y las listas de los más tocados y vendidos se ven ocupadas por artistas y géneros musicales de fuera de la ciudad. El mercado musical brasileño será dominado por prácticas musicales que se desvinculan del referencial carioca, siempre cubriendo cada género musical con un ambiente pop. Aparte del sertanejo, desarrollado en los rodeos y plazas del interior de São Paulo y Goiás, grupos de los estados de São Paulo y Minas Gerais reprocesarán el samba a un referencial modernizador, incluidos canto y unísono, teclados, batería y disminuyendo la importancia de la guitarra de siete cuerdas (prácticamente ausente) y del cavaquinho. Las bandas Raça Negra y Só Pra Contrariar (SPC) alcanzarán índices de ventas y repercusión máximos, ocupando las listas de los más vendidos y más tocados en radios de todo Brasil (Trotta, 2015). Al mismo tiempo, la música de carnaval de Salvador va a dominar el repertorio festivo, también con un ropaje sonoro que incluye guitarras, metales y mucha percusión. El grupo É o Tchan, reconocido por los bailes sensuales de las bailarinas Carla Perez y Sheila Melo, será el principal representante de este segmento (hombro a hombro con las cantantes Daniela Mercury e Ivete Sangalo), apodado peyorativamente axé music ${ }^{10}$.

Los tres géneros musicales, concebidos fuera de la urbanidad de las más grandes metrópolis nacionales (el llamado eje Río-São Paulo), encarnarán referenciales geográficos específicos (el samba fuera de Río, el interior y el carnaval bahiano) y serán duramente combatidos y criticados. Ahora bien, la intelectualidad urbana de Río y de la capital paulista todavía consigue mantener un referencial de prestigio que atribuye marcadores simbólicos para el juicio de calidad de la música popular. En este enfrentamiento, es relativamente fácil constatar que algunos críticos acaban por exhibir una especie de resentimiento estético que rechaza

10 El término axé es un saludo de origen afro que significa desear buenas energías, con amplio uso en la jerga cotidiana de Salvador. Se trata de una marca lingüística regional desplazada para denominar un estilo musical carnavalesco surgido en la ciudad y que se extendió por todo el país a finales de la década de 1980 e inicio de los años 1990. 
el protagonismo de otras regiones del país, ahora hegemónicas en la definición de éxitos nacionales. Un ejemplo ilustrativo de la violencia y del prejuicio estético y simbólico que rodea el éxito de esta nueva música pop nacional es una crítica de Pedro Alexandre Sanches, escrita en el diario Folha de São Paulo:

En el Imperio Unificado del Brasil Popular, todo el mundo tiene la misma cara. El trípode en donde se posiciona el mercado musical nacional - y no la música nacional, si se pudiera diferenciar-, todo se reconfigura en un ejército de mutantes sinvergüenzas. Axé, pagode y música sertaneja, las piernas del trípode, se alimentan y retroalimentan con reciprocidad. Hasta Carla Perez se cuelga del éxito del muchacho de esta banda, SPC. Pero es más pegajoso que la columna social de «Caras». Cuando quiere ser romántica, esta banda de pagode se vuelve sertaneja; cuando sale con una rumberita, parece Latino; para «abrasilerar» el rhythm'n'blues estadounidense, hace la versión de pop negro pegajoso $-\mathrm{y}$ es parecido a Ivete Sangalo queriendo cantar soul music con voz de mujer fatal (Sanches, 1999).

La agresividad supuestamente irónica del crítico revela un enorme prejuicio contra la música pop, reflejando una serie de argumentos bien conocidos que asocia el pop a la fabricación, repetición y falta de creatividad. Sin embargo, apunta indirectamente también a una posición de negativa a reconocer la posibilidad de las sonoridades pop de ser producidas en territorios de menor prestigio cultural. Como telón de fondo, los debates sobre forró electrónico y música sertaneja están impregnados de prejuicios regionales arraigados en el imaginario nacional (concebido y elaborado en Río), que se materializan estéticamente en torno a las terceras paralelas, a la sanfona y al uso de los teclados. Por otra parte, el samba, que se vuelve comercial y también se acerca a esta estética va a sufrir los mismos prejuicios, con el agravante de distanciarse de sus referencias consagradas en los cerros de la antigua capital federal (Trotta, 2015). Y se mezcla en este ambiente un fuerte componente de prejuicio racial y social, dirigido violentamente contra el funk, frecuentemente asociado con la estética de menor valor, las páginas policiales y la falta de creatividad (según criterios casi eruditos de consagración). Lo que aflora en todos estos casos es la amplia gama de tensiones, conflictos y rechazos que la circulación de música por los mercados nacionales activa, levantando debates estéticos profundos, fuertemente anclados en imaginarios geográficos y territoriales. 


\section{MÚSICA Y POLÍTICA: ENFRENTAMIENTOS SONOROS E INCOMODIDADES RECÍPROCAS}

En las páginas iniciales de su influyente libro, How musical is man?, el etnomusicólogo John Blacking afirma que la «música es el producto del comportamiento de grupos humanos», destacando que, en todas las sociedades, la definición de música se basa en algún tipo de «consenso de opiniones sobre los principios mediante los cuales los sonidos musicales se organizan» (2000, p. 10). El énfasis del autor en los procesos de producción de «consensos» en torno a la práctica musical prepara el camino de un largo debate sobre las funciones y usos de la música en las sociedades, normalmente apuntando a aspectos positivos de esta relación, como la construcción de identidades, pertenencias o afinidades colectivas. Como afirma la socióloga Tia De Nora, la música posee capacidad de gestión y de construcción del self, siendo un objeto cultural extremamente poderoso para producir cambios de estado físico y emocional (2000). A su vez, el trabajo de Blacking, De Nora y varios otros investigadores recalca que la música es una «forma de acción y pensamiento humano» (Blacking, 1995, p. 225) y que posee «poder transformador» (De Nora, 2002, p. 48). En estos pasajes, gana relevancia la dimensión política de la experiencia musical, entendida como objeto que constituye un «espacio de deliberación pública» (Street, 2012, p. 8).

Al debatir la práctica musical y sonora como una acción política, el etnomusicólogo brasileño Samuel Araújo sostiene que la música es resultado de un trabajo en el que un determinado tiempo se invierte y que dicho tiempo produce una transformación. Según el autor, la música puede entenderse como un «trabajo acústico» (Araújo, 1992), término que se refiere:

a un gasto de energía humana en el fenómeno acústico, es decir, el fenómeno que involucra producción y propagación de energía vibracional (o, en esta época, de su simulacro), su recepción en el aparato auditivo o, finalmente, la sensación de sonido. Como cualquier otra forma de trabajo, por lo tanto, debe estar conectada a nociones de valor y, en segundo lugar, estar sujeta, bajo la hegemonía de las relaciones capitalistas, a nociones como intereses, acumulación, ganancia, intercambio y mercado no en términos de analogías estandarizadas sobreimpuestas, pero en términos de sus raíces con prácticas humanas y sociales (Araújo, 1992, pp. 43-44).

Mejor aún, la música pensada como trabajo acústico desempeña un papel crucial en el establecimiento y circulación de ideas y valores simbólicos compartidos, y por lo tanto, es agente de enfrentamientos y disputas en torno a ellas. 
A partir de este despliegue, es posible pensar en «gestiones» $\mathrm{y}$ «acciones» realizadas por la música que se alejan de este conjunto «positivo» de reflexión sobre la música en la sociedad, activando un determinado uso de la música que actúa como marcador de distinción y otredad, muchas veces atravesada por cierto grado de violencia (Johnson y Cloonan, 2009).

Dos marcadores se vuelven particularmente eficaces para producir calificaciones y descalificaciones asociadas y procesadas por la música. El primero son los géneros musicales. Configurados de modo contradictorio en torno a algunas convenciones (sonoras, simbólicas y sociales) relativamente conocidas y aceptadas por un grupo de personas (Fabbri, 1982), los géneros funcionan como referenciales de escucha, adhesión y rechazo, «un modo de dividir la experiencia y el conocimiento musical» (Janotti Jr., 2006, p. 6). Son puertas de entrada para un intenso debate sobre valores éticos y estéticos que la experiencia musical elabora $\mathrm{y}$, por ello, los géneros son atravesados por una serie de concepciones, conceptos y prejuicios vinculados a un conjunto de ideas que circula en torno a sus convenciones. El estigma del funk carioca, por ejemplo, está asociado estrechamente con el espacio social donde fue gestado, con un conjunto de estereotipos relacionados con el grupo social que inventa, reinventa, participa, crea y frecuenta sus bailes. Al mismo tiempo, la desconfianza de la crítica cultural y las élites intelectuales y financieras brasileñas con respecto al funk está estrechamente relacionada con los espacios territoriales donde este surgió (Pereira de Sá, 2007). Y aquí somos llevados a un segundo marcador — que nos interesa más de cerca para este texto-, que es el marcador geográfico.

Como afirma el geógrafo Rogerio Hasbaert, el territorio articula una noción de poder que opera tanto en el sentido de dominación física como en el aspecto más simbólico (Hasbaert, 2005, p. 6774). Cuando asociamos música y territorio, resaltamos esta dimensión política de articulaciones simbólicas en torno a los territorios, accionadas cotidianamente a través de pertenencias y ufanidades, pero también de estigmatizaciones y prejuicios. Lo que es interesante observar es que no existen necesariamente dos momentos distintos de establecimiento de una relación positiva o negativa con músicas demarcadas espacialmente. El mismo movimiento, por ejemplo, que produce en gran parte de los habitantes del Nordeste brasileño el reconocimiento de que el forró es la materialización sonora de una serie de ideas que unifican una identidad nordestina produce, simultáneamente, rechazo de la población brasileña (del centro-sur e incluso del propio Nordeste), que identifica en esta asociación musical y territorial señales de elementos inferiorizados en las jerarquías simbólicas de la geografía nacional. 
Es decir, una misma práctica musical produce adhesión y rechazo, actuando como vector de valorización y depreciación por grupos sociales distintos.

Durval Muniz de Albuquerque Jr., al debatir el prejuicio sobre el origen geográfico en Brasil, observa que esas descalificaciones territoriales son también articuladas con jerarquías sociales:

En el Brasil de hoy, las personas pueden ser estigmatizadas por habitar una determinada región de la ciudad: habitar el morro o habitar la zona norte en Río de Janeiro o en Natal es ser marcado por el estigma y el prejuicio [...] Las segregaciones espaciales, en Brasil, acompañan sus segregaciones sociales. Tenemos una geografía de la exclusión y del miedo (Albuquerque Jr., 2012, p. 88)

En esta «geografía de la exclusión», la música desempeña un papel importante de actualizar, problematizar, explicar y crear continuamente los valores segregadores. En la reiteración de sonoridades identificadas con ciertos territorios, las jerarquías establecidas entre diferentes lugares y regiones se publicitan y son experimentadas y reelaboradas durante la experiencia. $Y$ el accionamiento de esta vinculación entre territorio, músicas y sentimentos compartidos configura y tensa las propias jerarquías, muchas veces cosificando sus bases y otras negándolas.

Es evidente que este fenómeno no se restringe a Brasil. En un estudio sobre las relaciones entre música, territorio y emoción en la música colombiana, Óscar Hernández Salgar discute el proceso de construcción de una oposición entre la melancolía indígena de la música andina de Bogotá y la alegría afrocaribeña de la música costera del país, que se volvió hegemónica en la construcción de una «música colombiana» (Hernández Salgar, 2016). Su investigación señala que determinados aspectos sonoros, sociales y políticos producirán una elaboración conflictiva sobre valores y modos de ser de la identidad colombiana que vinculaban elementos étnicos con emociones y geografía. El reconocimiento de que una región del país presenta en su música características «alegres» y otra región tenga como característica una música «melancólica» revela una manera de vincular marcas territoriales con imaginarios simbólicos, afectivos y comportamentales.

De manera similar, la cumbia villera en Argentina crea políticamente un sentimiento compartido de segregación social que se manifiesta en vinculaciones territoriales. El «villero» de su propia denominación asocia el estilo musical a una serie de descalificaciones sociales y étnicas que conducen a tensiones políticas y sociales en el país, absorbido por su público: «miembros jóvenes de los sectores populares urbanos, habitantes de los barrios pobres o de «"villas miserias"» 
(Silba, 2011, p. 296). El origen geográfico y social del modo «villero» de hacer, tocar y bailar la cumbia es un marcador importante a partir del cual las jerarquías sociales se piensan y procesan. El territorio se convierte en un símbolo que, por un lado, criminaliza y descalifica la práctica musical y todo lo que la rodea, pero, por otro, glamoriza y amplifica el alcance de los discursos sobre el espacio, su música y su público.

Se trata de un caso bastante similar al discutido por Micael Herschmann en su estudio sobre el funk en Brasil de inicios de la década de 1990. Según él, la práctica musical permite a determinados grupos urbanos «denunciar la condición de 'proscritos' y reivindicar ciudadanía» (2005, p. 119).

La construcción demonizada del otro puede justificar contra él actos de violencia o incluso su prohibición [...] pero trae numerosas dudas y pone en jaque la imagen de una supuesta cohesión del tejido social. Así, además del proceso de criminalización que afecta este grupo urbano, trae a colación, para el debate en la esfera pública, la discusión del lugar del pobre, o, mejor dicho, su derecho al entretenimiento y al «acceso» a la ciudad. (Herschmann, 2005, p. 119, cursiva original).

Avanzando en esta dirección, es importante destacar que la práctica musical presenta, en estos casos, la capacidad de explicar tensiones y conflictos de diversos tipos, elaborándolos a partir de su circulación en la sociedad. Lo que estoy queriendo señalar aquí es que esta acción esencialmente política ocurre a través de la fuerza expresiva de la música como detonante de incomodidades sonoras, estéticas, éticas y sociales. Cada uno de los casos discutidos aquí refleja modos de negociar los enfrentamientos sociales que se articulan también de maneras distintas con ciertos vínculos territoriales establecidos. Si la descalificación estética del forró está fuertemente vinculada con determinadas ideas de atraso, arcaísmo y tradicionalidad del propio imaginario del nordeste, en el caso del funk y del pagode la negación estética atraviesa una jerarquización inferiorizada que incorpora estigmas relacionados con clase social e identidad negra, materializados territorialmente en el espacio físico y simbólico de las favelas y suburbios. El caso de la música sertaneja apunta hacia otro eje, no necesariamente estigmatizada por una vinculación a la pobreza o arcaísmo sino a un prejuicio contra el «nuevo rico» del interior, distante de los imaginarios cosmopolitas reconocidos como válidos por las élites tradicionales de las metrópolis brasileñas. Se trata, en este caso, de una inferiorización estética que niega tanto un determinado conjunto de valores asociados al origen territorial de la música sertaneja, como al bajo 
reconocimiento de su autenticidad por la incorporación estética de signos sonoros, visuales y comportamentales del mundo pop.

En este ambiente complejo y de intensas disputas, las prácticas musicales organizadas en torno a etiquetas que identifican géneros, territorios y estilos operan como fuerzas de procesamiento y elaboración identitaria, social y política, generando conflictos y negativas, así como adhesiones y pertenencias. En el caso de un país continental como Brasil, esta diversidad sonora y regional da lugar a un ambiente ruidoso, en el cual las diferencias y separaciones tienden a ser, por lo menos, intensas en cuanto a las síntesis o consensos. Sin embargo, esta misma cacofonía simbólica permite la experiencia de tensiones y convivencias (no siempre amigables) entre ideas distintas sobre cada región, cada espacio de las ciudades y sobre la propia noción de nacionalidad, y también que, nuevamente a través de la música, algunas zonas de contacto logran establecerse. Se trata, finalmente, de las dificultades, desafíos y riqueza de la vida en sociedad, «sonoramente organizada» (Blacking, 2000, p. 3) y, al mismo tiempo, continuamente desorganizada.

\section{REFERENCIAS BIBLIOGRÁFICAS}

Albuquerque Jr., Durval Muniz de (2009). A invenção do Nordeste e outras artes. São Paulo: Cortez.

Albuquerque Jr., Durval Muniz de (2012). Preconceito contra origem geográfica e de lugar. São Paulo: Cortez.

Alonso, Gustavo (2015). Cowboys do asfalto: música sertaneja e modernização brasileira. Río de Janeiro: Civilização Brasileira.

Araújo, Samuel (1992). Acoustic labor in the timing of everyday life [Trabajo acústico al compás de la vida cotidiana]. Tesis de Doctorado. Musicología. Universidad de Illinois en Urbana-Champaign.

Blacking, John (1995). Music, culture and experience. Chicago, IL: Chicago University Press.

Blacking, John (2000). How musical is man? Seattle y Londres: University of Washington Press.

Connel, John y Chris Gibson (2003). Sound tracks: popular music, identity and place. Londres, Nueva York: Routledge. https://doi.org/10.4324/9780203448397

Essinger, Silvio (2005). Batidão: uma história do funk. Río de Janeiro y São Paulo: Record. 
Fabbri, Franco (1982). A theory of music genres: two applications. En D. Horn y P. Tagg (orgs.), Popular Music Perspectives (pp. 52-81). Gotemburgo y Exeter: IASPM.

Freyre, Gilberto (2004). Nordeste: aspectos da influência da cana sobre a vida e a paisagem do Nordeste do Brasil. São Paulo: Global.

Haesbaert, Rogerio (2005). Da desterritorialização à multiterritorialidade. Anales $X$ Encuentro de Geógrafos de América Latina. USP. Disponible en http://www. planificacion.geoamerica.org/textos/haesbaert_multi.pdf (acceso 3/dic/2016).

Hernández Salgar, Óscar (2016). Los mitos de la música nacional: poder y emoción en las músicas populares colombianas (1930-1960). La Habana, Cuba: Casa de las Américas.

Herschmann, Micael (2005). O funk e o hip hop invadem a cena. Río de Janeiro: UFRJ.

Janotti Jr., Jeder (2006). Mídia, música popular massiva e gêneros musicais. Anales XV Encuento de la Compós. Bauru, SP: Unesp.

Janotti Jr., Jeder (2015). Rock me like the devil. Recife: Papel Finíssimo.

Johnson, Bruce y Martin Cloonan (2009). Martin. The Dark Side of the Tune. Farnhan, Reino Unido y Burlington, EE.UU.: Ashgate.

Mendívil, Julio (2016). En contra la música. Buenos Aires: Gourmet Musical.

Nepomuceno, Rosa (2005). Música caipira: da roça ao rodeio. São Paulo: Ed. 34.

Oliveira, Luciana Xavier (2016). A cena musical da Black Rio: mediações e políticas de estilo nos bailes soul dos suburbios cariocas dos anos 1970. Tesis de Doctorado. Programa de Posgraduación en Comunicación. Niteroi, RJ: UFF.

Ortiz, Renato (2001). A moderna tradição brasileira. São Paulo: Brasiliense.

Palombini, Carlos (2010). Notes on historiography of música soul and funk carioca. História Actual On Line, 23. Cádiz, España: Universidad de Cádiz.

Penna, Maura (1992). O que faz ser nordestino. São Paulo: Cortez.

Pereira de Sá, Simone (2007). Funk carioca: música eletrônica popular brasileira? Revista E-Compós, 10. Brasilia: Compós.

Regev, Motti (2013). Pop-rock music. Cambridge, Reino Unido y Malden, EE.UU.: Polity Press.

Sandroni, Carlos (2012). Feitiço decente: transformações no samba no Rio de Janeiro (1917-1933). Río de Janeiro: Zahar.

Santos, Climério (2014). Forró desordeiro. Tesis de Doctorado. Programa de Posgraduación en Música. Río de Janeiro: Uni-Rio. 
Silba, Malvina (2011). La cumbia en Argentina: origen social, públicos populares y difusión masiva. En Pablo Semán y Pablo Vila (orgs.), Cumbia: nación, etnia y género en Latinoamérica (pp. 247-296). Buenos Aires: Gorla.

Street, John (2012). Music and politics. Cambridge, Reino Unido y Malden, EE.UU.: Polity Press.

Trotta, Felipe (2014). No Ceará não tem disso não: nordestinidade e macheza no forró contemporáneo. Río de Janeiro: Folio Digital.

Trotta, Felipe (2015). Samba and Music Market in Brazil in the 1990's. En Made in Brazil: Studies in Popular Music. Nueva York y Londres: Routledge.

Trotta, Felipe (2016). O funk no Brasil contemporâneo: uma música que incomoda. Latin America Research Review (LARR), 51(4), 88-101. Pittsburgh, PA: University of Pittsburgh Press. https://doi.org/10.1353/lar.2016.0050

Trotta, Felipe y Monteiro, Marcio (2008). O novo mainstream da música regional. Revista E-Compós, 11(2). Brasilia: Compós, mayo-agosto.

Vianna, Hermano (1995). O mistério do samba. Río de Janeiro: UFRJ. 